\title{
Sponsor Protocol Identifier
}

National Cancer Institute

\section{Source}

National Cancer Institute. Sponsor Protocol Identifier. NCI Thesaurus. Code C132351.

A unique code, which is assigned by the sponsor, that identifies a specific protocol. 